The use of height-adjustable, three-point seat belts became mandatory, as well as Child Restraint Systems for children under 3 years of age.

The campaign "Back to School Safely" is carried out annually highlighting the importance of appropriate safety elements for children and their correct use.

Conclusions Although work carried out so far has been praised in different occasions and has raised awareness among adults, there still much to do especially regarding enforcement.

In 2015, the FGR started a study on School Transport regulation and market in ten different countries. Results are expected to provide a clear picture of the steps to follow by each country to have regulations and fleets that reduce the number of fatalities and injured among children in road crashes involving School Transport.

\section{PREDICTION OF ROAD TRAFFIC CRASHES (RTC) IN SRI LANKA FROM 2015 TO 2025}

${ }^{1}$ Achala Upendra Jayatilleke, ${ }^{2}$ Achini Jayatilleke. ${ }^{1}$ Postgraduate Institute of Medicine, University of Colombo, Colombo, Sri Lanka; ${ }^{2}$ Family Planning Association of Sri Lanka, Colombo, Sri Lanka

\subsection{6/injuryprev-2016-042156.371}

Background Under the sustainable development goals (SDG), Sri Lanka is planning to halve the road traffic deaths and injuries by 2030. The main obstacle for achieving this goals is lack of accurate data. Road traffic crashes (RTC) are largely under-reported in Sri Lanka after 2003. Therefore, we conducted this study to estimate the number of under-reported RTCs, and predict the number of actual crashes and injuries up to 2030 using data from 1977 to 2014.

Methods We extracted RTC data for 1977 to 2014 from an interim report on RTCs of a Parliamentary Select Committee and from the official web site of the Sri Lanka Police. We analysed extracted data using Microsoft Excel and R. We calculated crash, injury, and fatality rates per 100,000 population and carried out the prediction using 'forecast' package in R.

Results Between 1977 and 2003, total crash rate increased from 109.7 to 310.7 , minor injuries increased from 44.2 to 61.4 , grievous injuries increased from 6.0 to 18.0 , and deaths increased from 5.8 to 10.6 per 100,000 population. From 2003 to 2014, total crash rate decreased from 310.7 to 165.6 , minor injuries decreased from 61.4 to 59.7 and damage only crashes decrease from 187.1 to 64.2 per 100,000 population. According to the analysis, this was a false reduction, and 334,328 damage only crashes and 18,683 minor injury crashes have been underreported between 2003 and 2014. However, fatalities and grievous injury crashes were not under-reported. Accordingly, by 2025 , total crashes will increase to 480.7 , damage only crashes will increase to 339.7 , minor injuries will increase to 71.8 , and grievous injuries will increase to 30.4 per 100,000 population. fatality rate will not increase in similar intensity.

Conclusion Under-reporting of RTCs is masking its rapid increase in Sri Lanka. To achieve SDG on RTCs, Sri Lankan policy makers have to take this under-reporting in to consideration and might use this prediction to allocate funds and resources for prevention of RTCs.

\section{THE IMPACT OF ROAD SAFETY CAMPAIGN ON MOTOR CYCLE RELATED ROAD TRAFFIC INJURIES IN NAIVASHA, KENYA}

${ }^{1}$ Walter A Odhiambo, 'Saidi Hasan, ${ }^{2}$ Charles Mock, ${ }^{1} J u l i u s$ Oyugi, ${ }^{1}$ Walter Mwanda, ${ }^{1}$ Isaac Kibwage. ${ }^{1}$ College of Health Sciences, University of Nairobi, Kenya; ${ }^{2}$ Department of Global Health, University of Washington, Seattle, USA

\subsection{6/injuryprev-2016-042156.372}

Background Kenya was identified as one of the ten priority countries in the WHO led UN Decade of Action for Road Safety (2011-2020) that aimed at reducing global road crash injuries and mortality by at least 50\%, through a systematic road safety campaign by 2020 . The Road safety campaign in 10 -countries or RS-10 as the campaign was known, targeted ten worst hit countries that together accounted for about $50 \%$ of global road crash fatalities.

The Kenyan project dubbed Road Safety Kenya (RS-K) identified the highway towns of Thika and Naivasha as the 5-year pilot implementation sites. The project started in the year 2010, and one of the interventions was the campaign to promote the wearing of helmets by motor cycle (MC) riders and their passengers. Helmets have been shown to reduce mortality and severity of head injuries among MC riders.

The objective of this study was to assess the impact of road safety campaign targeting MC riders since the year 2010 in Naivasha, Kenya.

Methods Cross sectional observational study in which MC road safety compliance as evident in use of protective helmets by rider and passengers, use of reflective clothing by rider and passenger as well as the use of daytime riding lights was directly observed by the roadside.

Results A total of 9280 motor cycles were observed from the 6 study centres during the 7-day data collection period. Of these only $18 \%$ (1752) complied with all the three road safety measures of wearing helmet by passenger and rider, reflective jacket and one pillion passenger at any single time. Helmet compliance was $42 \%(3,850)$ among the riders and only $9 \%$ (402) passengers wore helmet while riding. Males were twice likely to wear helmets than the female counterparts. Luminous clothing were widely used by riders (76.2\%) while only 349 (3.8\%) rode with the headlight on at daytime.

Conclusion Despite the road safety campaign conducted in Naivasha between 2010 and 2014, the compliance with road safety measures among motor cycle riders remain low particularly among the passengers. It is probable that passengers were poorly targeted in this campaign due to logistical challenges or simply that the strategies that have been successful elsewhere are not applicable in this environment.

It should be useful to establish from a hospital and mortuary based research if females have a higher percentage of mortality and severe head injuries due to poorer compliance with helmet use. 